\title{
The employment of FTIR spectroscopy and chemometrics for authentication of pumpkin seed oil from sesame oil
}

\author{
${ }^{1,2}$ Irnawati, ${ }^{1}$ Riyanto, S., ${ }^{1}$ Martono, S. and ${ }^{1,3,{ }^{*}}$ Rohman, A. \\ ${ }^{1}$ Department of Pharmaceutical Chemistry, Faculty of Pharmacy, Universitas Gadjah Mada, Yogyakarta \\ ${ }^{2}$ Faculty of Pharmacy, Universitas Halu Oleo Kendari, Southeast Sulawesi 93232 Indonesia. \\ ${ }^{3}$ Institute of Halal Industry and Systems, Universitas Gadjah Mada, Yogyakarta 55281 Indonesia
}

Article history:

Received: 12 May 2019

Received in revised form: 16

July 2019

Accepted: 18 July 2019

Available Online: 30 July 2019

Keywords:

Pumpkin seed oil,

Sesame oil,

FTIR spectroscopy,

Discriminant analysis,

Authentication analysis

DOI:

https://doi.org/10.26656/fr.2017.4(1).198

\begin{abstract}
The adulteration practice of high price oils such as pumpkin seed oils (PSO) with lower ones could be motivated by economic gains. The objective of this study was to apply FTIR spectroscopy in combination with chemometrics of multivariate calibrations and discriminant analysis for the authentication of PSO. A total of fifteen oils were scanned using FTIR spectrophotometer at mid-infrared regions $\left(4000-650 \mathrm{~cm}^{-1}\right)$ and subjected to principal component analysis (PCA) using absorbance values at whole mid-IR regions to know oil having a close similarity to PSO in terms of FTIR spectra. Two multivariate calibrations namely principle component regression (PCR) and partial least square regression (PLSR) along with FTIR spectra modes (normal, derivative-1, and derivative2) were optimized to get the best prediction models. In addition, discriminant analysis (DA) was used for classification of PSO and PSO adulterated with oil adulterant. The results showed that among 15 oils, sesame oil $(\mathrm{SeO})$ had the closer score plot in terms of the first principle component and second principle components with that of PSO. Based on the statistical parameters selected (higher $\mathrm{R}^{2}$ and lowest errors), FTIR spectra in derivative -1 mode at wavenumbers of $1800-663 \mathrm{~cm}^{-1}$ were selected for quantification of PSO in $\mathrm{SeO}$ with coefficient of determination (R) values of 0.9998 and 0.9994 in calibration and validation models, respectively. The values of root mean square error of calibration (RMSEC) and root mean square error of prediction obtained were $0.003 \%$ and $0.006 \%$, respectively. DA using 10 principle components could clearly discriminate PSO and PSO adulterated with $\mathrm{SeO}$ with accuracy levels of $100 \%$. FTIR spectroscopy in combination with chemometrics could be an effective means to detect the adulteration of PSO with $\mathrm{SeO}$.
\end{abstract}

\section{Introduction}

Pumpkin (Cucurbita maxima) belongs to Cucurbitaceae family which widely grows in tropical regions and has a relatively high economic importance around the world. Food industry has exploited to use pumpkin for the production of juices, purees, jams and alcoholic beverages (Jiao et al., 2012). Meanwhile, pumpkin seed refers to the edible seed of a pumpkin, containing some bioactive compounds frequently used as herbal medicines and functional foods. Pumpkin seeds are also commonly used in culinary practices mainly in Southeast Asian countries. In Indonesia, pumpkin is one of the popular vegetables consumed as considered as a functional food due to the extraordinary rich sources of bioactive compounds having beneficial health effects (Montesano et al., 2018). In addition, pumpkin seed oil (PSO), a strongly dichromatic viscous oil extracted from pumpkin seed, has gained great attention in fats and oils industry not only as edible oil but also as a potential nutraceutical (Rezig et al., 2012).

PSO has been reported to contain phytosterols, phenolic compounds, antioxidants, tocopherols, and small levels of carotenoids responsible to some biological activities which are beneficial to human health (Cuco et al., 2019) including prevention of gastric, breast, colorectal and lung cancers (Elfiky et al., 2012), retardation of hypertension progression antihypertension (Zuhair et al., 2000), prevention of prostate disease, mitigation of hypercholesterolemia and arthritis, alleviation of diabetes mellitus by enhancing hypoglycaemic activity, reduction of bladder and urethral pressure (Fruhwirth et al., 2003), improving bladder compliance and urinary disorder in human overactive bladder (Nishimura et al., 2014), and offering 
good antioxidant sources (Naziri et al., 2016).

Due to the beneficial effects of PSO to human health, PSO has high price in the market, as a consequence, PSO may be adulterated with other oils. Thus, analytical methods which are reliable for adulteration analysis of PSO are highly needed. Some methods have been proposed, developed and used for authentication of PSO which include molecular spectroscopy (ultraviolet-visible, near-infrared, midinfrared spectroscopy) (Lankmayr et al., 2004), gas chromatography for analysis of $\Delta 7$-phytosterols (Mandl et al., 1999), liquid chromatography (Butinar et al., 2010), and carbon isotope analysis of the individual fatty acids by the use of gas chromatography-combustionisotope ratio mass spectrometry (GC/C/IRMS) (Spangenberg, 2001).

FTIR spectroscopy coupled with chemometrics has been used for authentication of high priced oils including authentication extra virgin olive oil from palm oil (Rohman and Che Man, 2010), authentication virgin coconut oil from palm oil (Rohman and Che Man, 2009), sesame oil from corn oil (Nurrulhidayah et al., 2014), beef fat from dog meat (Rahayu et al., 2018), and authentication of fish patin oil from palm oil (Putri et al., 2019). However, there is a limited study on the application of FTIR spectroscopy in combination with chemometrics for authentication of pumpkin seed oil (PSO). Therefore, this study was aimed to develop FTIR spectroscopy combined with multivariate calibrations and discriminant analysis for authentication of PSO from sesame oil.

\section{Materials and methods}

\subsection{Materials}

Pumpkin seed oil, canola oil, coconut oil, corn oil, extra virgin olive oil, garlic oil, ginger oil, grape seed oil, black seed oil, hazelnut oil, palm oil, rice bran oil, soya bean oil, sesame oil and sunflower oil were purchased from several markets in Yogyakarta, Indonesia. The fatty acids composition of pumpkin seed oil (PSO) and sesame oil $(\mathrm{SeO})$ were in agreement with those in Codex Alimentarius Commission and used to confirm that both oils were not adulterated previously with other oils. The solvents and reagents used were of pro-analytical grade.

\subsection{Principal component analysis of oils}

Pumpkin seed oil (PSO), canola, coconut, corn, extra virgin olive, garlic, ginger, grape seed, black seed, hazelnut, palm, rice bran, soya bean, sesame and sunflower oils were subjected to FTIR spectral measurements. Oils having close score plot value using absorbance values at whole mid-infrared regions with
PSO was used as oil adulterants. Based on this, sesame oil was selected as oil adulterant.

\subsection{Preparation of calibration and validation samples}

For quantitative analysis purposes, a series of calibration and validation (prediction) samples with known concentrations of PSO were prepared. For making calibration samples, 20 samples consisting of PSO in binary mixtures with $\mathrm{SeO}$ at concentration ranges of $0-100.0 \% \mathrm{v} / \mathrm{v}$ were prepared. The oil concentrations were selected randomly with the aid of Excel software (Microsoft Inc., USA). For preparing validation samples, a series of different samples was preparing in the concentration ranges covered by calibration samples. All samples were analyzed using FTIR spectrophotometer.

\subsection{Discriminant analysis}

For discriminant analysis (DA), pure PSO and PSO adulterated with $\mathrm{SeO}$ in the concentration range of 0.5 $50.0 \%(\mathrm{v} / \mathrm{v})$ was prepared. Pure PSO was assigned as authentic, meanwhile, PSO mixed with $\mathrm{SeO}$ was called as adulterated. Both classes (unadulterated and adulterated samples) were classified and discriminated using DA on the basis of their FTIR spectra.

\subsection{FTIR spectra acquisition}

The acquisition of FTIR spectra of studied samples was performed using FTIR spectrometer (Thermo Scientific Nicolet iS10, Madison, WI), controlled with the operating Omnic software. The measurements were done in mid-infrared region of $4000-650 \mathrm{~cm}^{-1}$ with 32 scanning and the resolution was $8 \mathrm{~cm}^{-1}$ using horizontal attenuated total reflectance (HATR) composed of $\mathrm{ZnSe}$ crystal. All FTIR spectra were corrected against FTIR spectrum of air as background. After every scan, a new reference air background spectrum was taken. These spectra were recorded as absorbance values at each data point in triplicate.

\subsection{Chemometrics analysis}

Chemometrics analysis including multivariate calibration and discriminant analysis was performed using TQ Analyst software version 9 (Thermo Fisher Scientific, Inc.). For quantification, multivariate calibrations used were PLS and PCR. Principal component analysis was carried out using software Minitab version 17 (Minitab Inc., USA).

\section{Results and discussion}

In this study, FTIR spectroscopy in combination with several chemometrics techniques namely principal component analysis (PCA), multivariate calibrations of principle component regression (PCR), partial least 
square regression (PLSR) was used for authentication of pumpkin seed oil (PSO). PCA was used to look for oils having similar characteristics to PSO, as depicted as score plot of first principle component analysis (PC1) and second principle component (PC2) using absorbances at whole mid-infrared region $\left(4000-650 \mathrm{~cm}^{-}\right.$ ${ }^{1}$ ) as variables. As shown in Figure 1, FTIR spectrum of sesame is similar to that of sesame oil $(\mathrm{SeO})$, therefore $\mathrm{SeO}$ was selected as oil adulterant. This indicated that PSO and $\mathrm{SeO}$ had a similar FTIR spectrum. Besides, both oils physically also have similar color.

Figure 2 reveals FTIR spectra of sesame oil $(\mathrm{SeO})$ and pumpkin seed oil (PSO) scanned at mid-infrared regions corresponding to wavenumbers of $4000-650 \mathrm{~cm}^{-1}$ using attenuated total reflectance as a sampling technique. Both FTIR spectra showed the typical infrared spectra of tryglycerides (TG) and this is not surprising because edible oils are mainly composed from TGs (Jimenez-Carvelo et al., 2017). Each shoulders and bands (peaks) related to absorption of infrared radiation by functional groups present in $\mathrm{SeO}$ and $\mathrm{PSO}$. Peak at 3007 was due to stretching vibration of cis $\mathrm{C}=\mathrm{CH}$, while the peak at $2953 \mathrm{~cm}^{-1}$ originated from asymmetric stretching vibration of methyl $\left(-\mathrm{CH}_{3}\right)$ group. The peaks at 2922 and $2853 \mathrm{~cm}^{-1}$ were coming from asymmetric and symmetric stretching vibrations of methylene $\left(-\mathrm{CH}_{2}\right)$. The carbonyl $(\mathrm{C}=\mathrm{O})$ stretching vibration was observed at $1744 \mathrm{~cm}^{-1}$, while the peak at 1654 is from $\mathrm{C}=\mathrm{C}$ stretching vibration. The bending vibrations of methylene and methyl were observed at wavenumbers of 1460 and $1376 \mathrm{~cm}^{-1}$, respectively. The peaks at regions of $1237,1160,1118$, 1098 were from C-O vibrations. While, peaks at 996 and 850 were due to bending out of plane vibrations of $\mathrm{HC}=\mathrm{CH}-$ (trans) and $-\mathrm{HC}=\mathrm{CH}-($ cis $)$, respectively (Ozulku et al., 2017; Arslan et al., 2019).

Due to the nature of FTIR spectra as fingerprint analytical tools, the variation in FTIR spectra of PSO and $\mathrm{SeO}$ existed, and this difference was exploited for

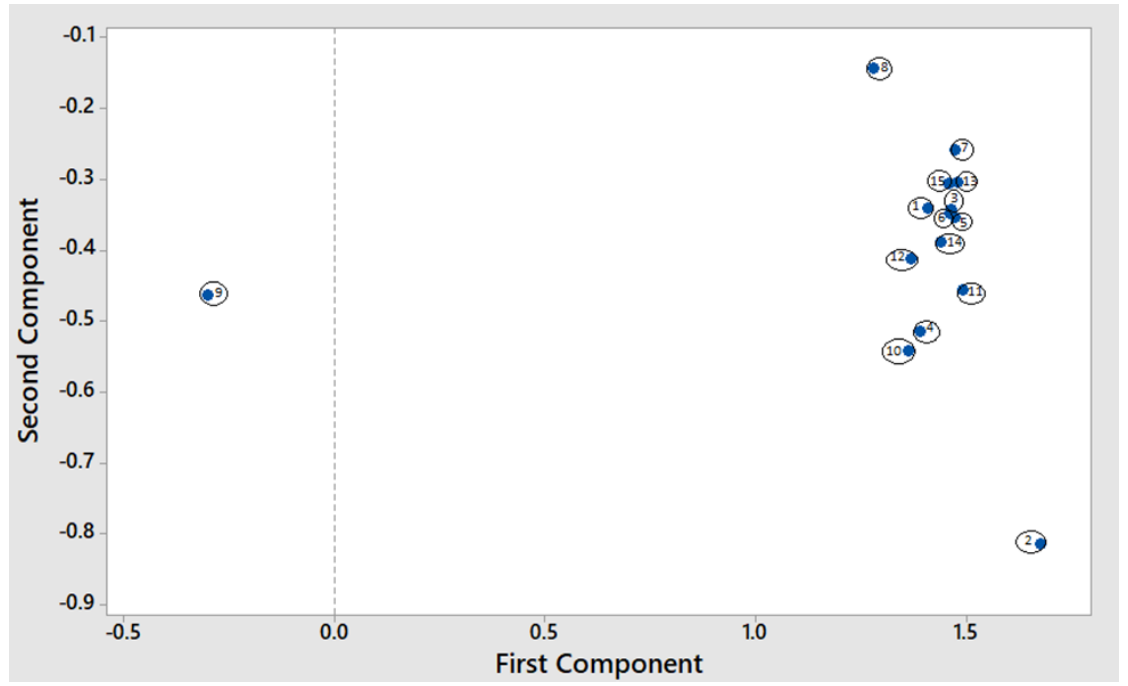

Figure 1. The PCA score plot of pumpkin seed oil (11) and other oils. $1=$ Canola Oil; 2 = Coconut Oil; $3=$ Corn Oil; $4=$ Extra Virgin Olive Oil; $5=$ Garlic Oil; $6=$ Ginger Oil; $7=$ Grape Seed Oil; $8=$ Black seed Oil; $9=$ Hazelnut Oil; $10=$ Palm Oil; $12=$ Rice Bran Oil; 13 =Soya Bean Oil; 14 = Sesame Oil; and 15 = Sun Flower Oil.

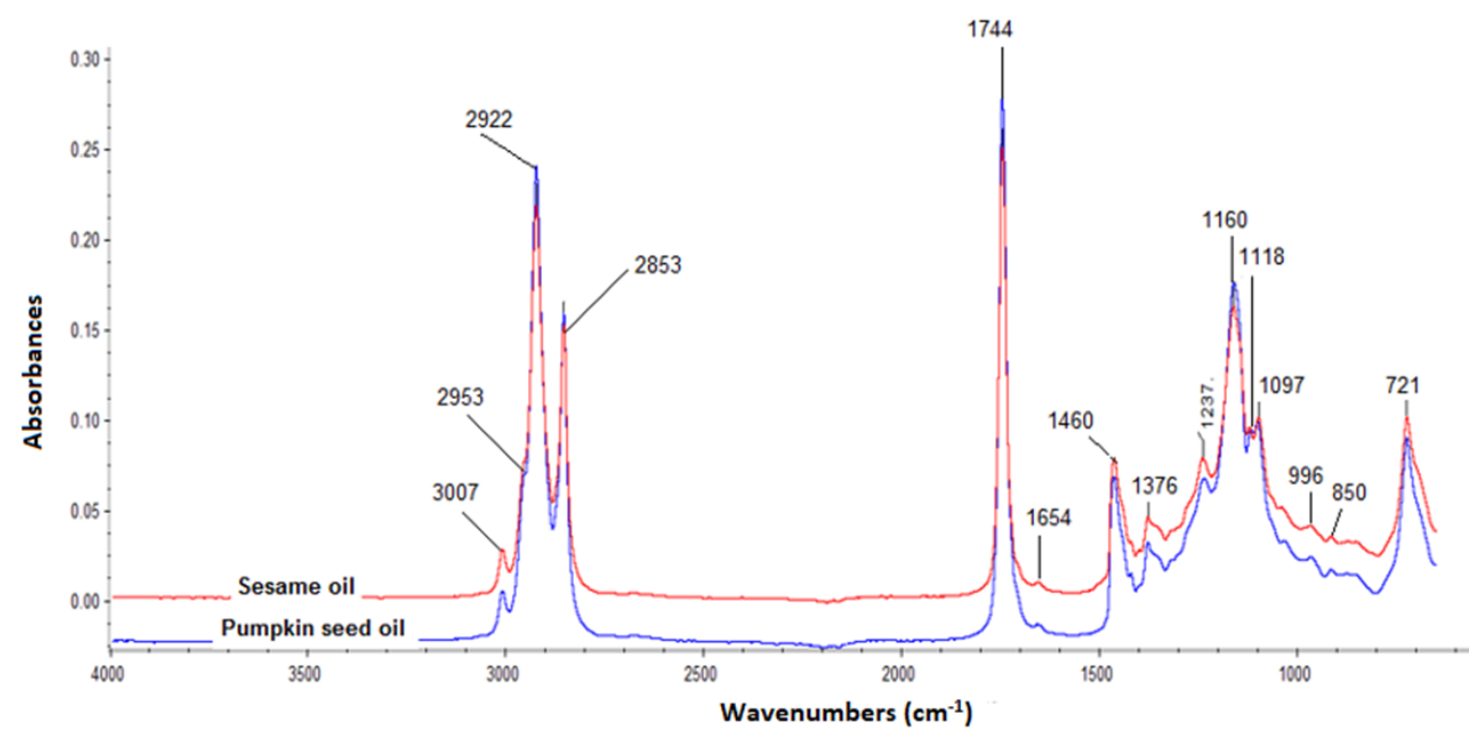

Figure 2. FTIR spectra of pumpkin seed oil and sesame oil scanned at mid infrared region (4000-650 $\left.\mathrm{cm}^{-1}\right)$ using attenuated total reflectance mode. 
Table 1. The results of FTIR spectroscopy using different wavenumbers and spectral treatments coupled with multivariate calibration intended for prediction of pumpkin seed oil (PSO) levels adulterated with sesame oil.

\begin{tabular}{|c|c|c|c|c|c|c|}
\hline \multirow{2}{*}{ Multivariate calibrations } & \multirow{2}{*}{ Wavenumber $\left(\mathrm{cm}^{-1}\right)$} & \multirow{2}{*}{ Spectra } & Calibration & \multicolumn{3}{|c|}{ Validation } \\
\hline & & & $\mathrm{R}^{2}$ & RMSEC & $\mathrm{R}^{2}$ & RMSEP \\
\hline \multirow{18}{*}{ PCR } & \multirow{3}{*}{$3100-663$} & normal & 0.9978 & 0.0096 & 0.9773 & 0.0134 \\
\hline & & derivative 1 & 0.9982 & 0.0086 & 0.9975 & 0.0111 \\
\hline & & derivative 2 & 0.9918 & 0.0188 & 0.9935 & 0.0052 \\
\hline & \multirow{3}{*}{$1800-663$} & normal & 0.9984 & 0.0082 & 0.9983 & 0.0131 \\
\hline & & derivative 1 & 0.9989 & 0.0066 & 0.9988 & 0.0084 \\
\hline & & derivative 2 & 0.9971 & 0.011 & 0.9964 & 0.015 \\
\hline & \multirow{3}{*}{$3100-2750$} & normal & 0.9955 & 0.0136 & 0.9894 & 0.0213 \\
\hline & & derivative 1 & 0.9866 & 0.0235 & 0.9824 & 0.0288 \\
\hline & & derivative 2 & 0.9459 & 0.0468 & 0.9265 & 0.0558 \\
\hline & \multirow{3}{*}{$1500-663$} & normal & 0.9989 & 0.0066 & 0.9993 & 0.0056 \\
\hline & & derivative 1 & 0.999 & 0.0063 & 0.9991 & 0.0063 \\
\hline & & derivative 2 & 0.9972 & 0.0109 & 0.9981 & 0.0098 \\
\hline & \multirow{3}{*}{$\begin{array}{c}3100-2750 \text { and } \\
1800-663\end{array}$} & normal & 0.9985 & 0.0078 & 0.9984 & 0.0116 \\
\hline & & derivative 1 & 0.9992 & 0.0059 & 0.9987 & 0.0081 \\
\hline & & derivative 2 & 0.9972 & 0.0107 & 0.9966 & 0.0151 \\
\hline & \multirow{3}{*}{$\begin{array}{c}3100-2750 \text { and } \\
1500-663\end{array}$} & normal & 0.9975 & 0.0102 & 0.9976 & 0.0101 \\
\hline & & derivative 1 & 0.999 & 0.0065 & 0.9989 & 0.0069 \\
\hline & & derivative 2 & 0.9981 & 0.0089 & 0.9989 & 0.0081 \\
\hline \multirow{18}{*}{ PLS } & \multirow{3}{*}{$3100-663$} & normal & 0.9873 & 0.0229 & 0.9873 & 0.0236 \\
\hline & & derivative 1 & 0.9999 & 0.002 & 0.9989 & 0.0078 \\
\hline & & derivative 2 & 0.9979 & 0.0092 & 0.9947 & 0.0213 \\
\hline & \multirow{3}{*}{$1800-663$} & normal & 0.992 & 0.0182 & 0.9914 & 0.0236 \\
\hline & & derivative 1 & 0.9998 & 0.003 & 0.9994 & 0.0061 \\
\hline & & derivative 2 & 0.9996 & 0.0041 & 0.9975 & 0.0122 \\
\hline & \multirow{3}{*}{$3100-2750$} & normal & 0.9952 & 0.0141 & 0.9898 & 0.0209 \\
\hline & & derivative 1 & 0.993 & 0.017 & 0.9846 & 0.0267 \\
\hline & & derivative 2 & 0.9926 & 0.0175 & 0.967 & 0.0386 \\
\hline & \multirow{3}{*}{$1500-663$} & normal & 0.9981 & 0.0089 & 0.9971 & 0.0113 \\
\hline & & derivative 1 & 1 & 0.001 & 0.9992 & 0.0066 \\
\hline & & derivative 2 & 0.9996 & 0.0039 & 0.9992 & 0.0081 \\
\hline & \multirow{3}{*}{$\begin{array}{c}3100-2750 \text { and } \\
1800-663\end{array}$} & normal & 0.9981 & 0.0098 & 0.9971 & 0.0113 \\
\hline & & derivative 1 & 0.9999 & 0.0015 & 0.9992 & 0.0065 \\
\hline & & derivative 2 & 0.9979 & 0.0092 & 0.997 & 0.0148 \\
\hline & \multirow{3}{*}{$\begin{array}{c}3100-2750 \text { and } \\
1500-663\end{array}$} & normal & 0.9858 & 0.0242 & 0.9848 & 0.0252 \\
\hline & & derivative 1 & 0.9999 & 0.0018 & 0.9992 & 0.006 \\
\hline & & derivative 2 & 0.9997 & 0.0035 & 0.9989 & 0.0088 \\
\hline
\end{tabular}

\section{The selected variables were marked with bold.}

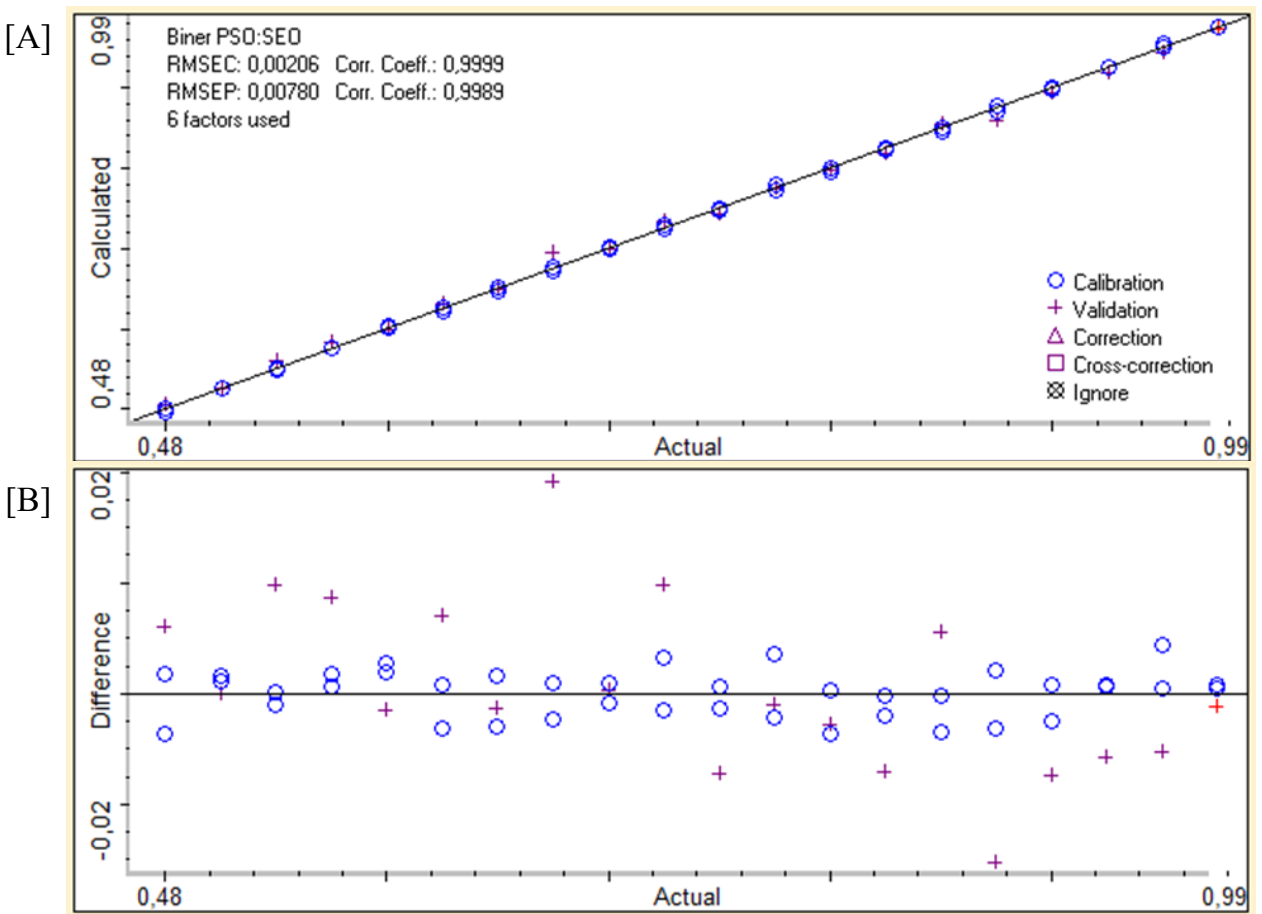

Figure 3. The relationship between actual values (x-axis) of pumpkin seed oil (PSO) in x-axis and the predicted values of PSO using FTIR spectroscopy [A] along with residual analysis [B]. 


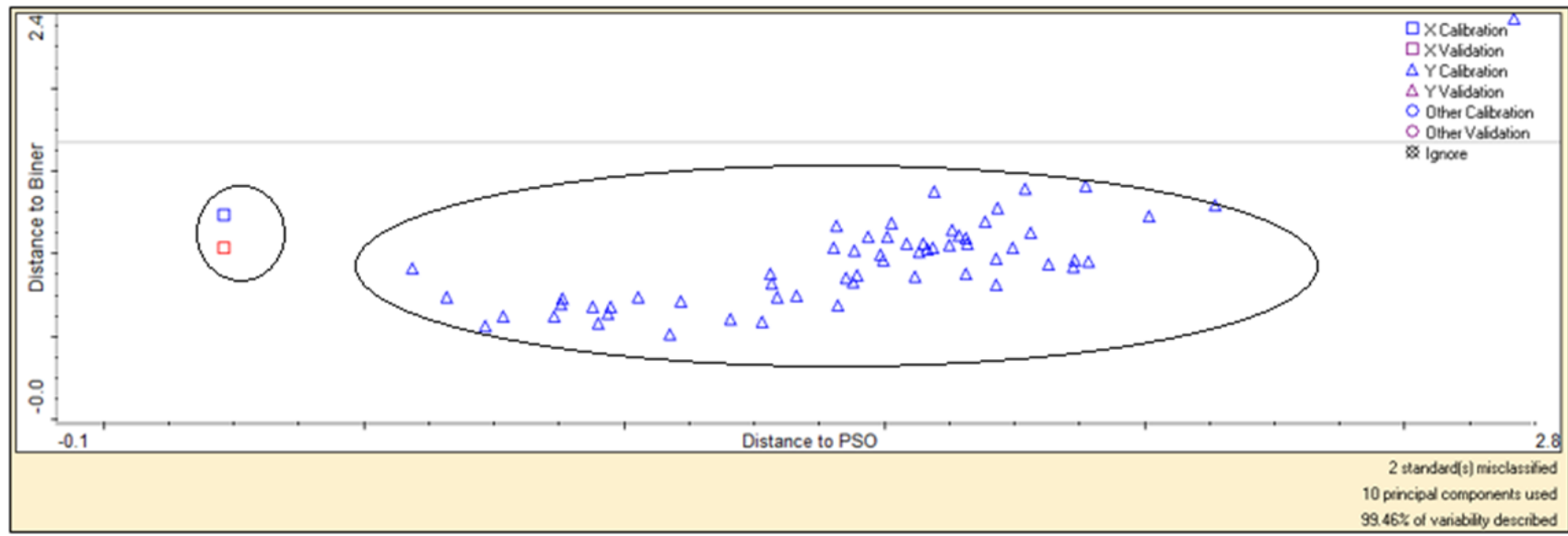

Figure 4. The Cooman's plot obtained during discriminant analysis for discrimination of pure pumpkin seed oil (PSO) and PSO mixed with sesame oil.

optimization of wavenumbers regions and spectral modes for quantitative analysis and discrimination analysis between PSO and PSO mixed with SeO. Quantitative analysis of PSO in $\mathrm{SeO}$ was performed with the aid of two multivariate calibrations, namely principle component regression (PCR) and Partial Least Square regression (PLS). Both PCR and PLSR are inverse regression in which concentration (y-axis) was modelled with predictors of principle components, a linear combination of absorbance values (x-axis) (Manaf et al., 2007).

In order to obtain the best prediction models, multivariate calibrations (PCR and PLSR), the wavenumbers regions and FTIR spectral treatments (normal, derivative-1 and derivative-2) were optimized. Table 1 compiles the optimization results by combining the parameters and the variables selected were based on the highest coefficient of determination $\left(\mathrm{R}^{2}\right)$ and the lowest errors. PLSR at wavenumbers of $1800-663 \mathrm{~cm}^{-1}$ was selected for quantification of PSO in $\mathrm{SeO}$ with $\mathrm{R}^{2}$ values of 0.9998 and 0.9994 in calibration and validation models, respectively. The values of root mean square error of calibration (RMSEC) and root mean square error of prediction obtained were $0.003 \%$ and $0.006 \%$, respectively. The high values of $\mathrm{R}^{2}$ and low values of RMSEC and RMSEP indicated that the developed models offered acceptable accuracy and precision. Figure $3 \mathrm{~A}$ reveals the correlation between actual values (x-axis) of PSO and the predicted values of PSO using FTIR spectroscopy. It is clear that errors occurring during modelling were randomly occured around zero difference. This indicated that the systematic errors did not existed and the model developed are reliable to predict $\mathrm{PSO}$ adulterated with $\mathrm{SeO}$.

The chemometrics of discriminant analysis (DA) is one of the supervised pattern recognition and is commonly used for clustering between authentic samples with adulterated ones (Rohman et al., 2014). The variables used during DA were absorbances at the whole mid-infrared region, and the Mahalanobis distances were then calculated using these absorbances. Figure 4 shows the Cooman's plot for classification purposes, and DA could classify PSO and PSO mixed with $\mathrm{SeO}$ successfully with the accuracy level of $100 \%$. This result indicated that DA as an effective tool to classify high priced edible oils from potential adulterants.

\section{Conclusion}

Fourier transform infrared (FTIR) spectroscopy in combination with PLSR and discriminant analysis was successfully used for quantification and classification of PSO adulterated with SeO. Derivative-1 FTIR spectra at wavenumbers of 1800-663 $\mathrm{cm}^{-1}$ coupled with PLSR was used for quantification, while FTIR normal spectra at whole mid-infrared region were exploited for classification using DA. FTIR spectroscopy in combination with chemometrics of PLSR and DA could be effective to detect the adulteration of PSO with $\mathrm{SeO}$.

\section{Conflict of Interest}

Authors declare no conflict of interest.

\section{Acknowledgement}

The authors thank the Ministry of Research, Technology and Higher Education, Republic Indonesia for financial support during this study through Hibah Penelitian Dasar Unggulan Perguruan Tinggi (PUPT) 2019 with contract number 2519/UN1.DITLIT/DIT-LIT/ LT/2019.

\section{References}

Arslan, F.N., Akina, G., Elmas S.N.K, Yilmaz, I., Janssen, H-G. and Kenar, A. (2019). Rapid detection of authenticity and adulteration of cold pressed black cumin seed oil: A comparative study of ATR-FTIR spectroscopy and synchronous fluorescence with 
multivariate data analysis. Food Control, 98, 323332. https://doi.org/10.1016/j.foodcont.2018.11.055

Butinar, B., Bučar-Miklavčič, M., Valenčič V. and Raspor, P. (2010). Stereospecific Analysis of Triacylglycerols as a Useful Means to Evaluate Genuineness of Pumpkin Seed Oils: Lesson from Virgin Olive Oil Analyses. Journal of Agricultural and Food Chemistry, 58(9), 5227-5234. https:// doi.org/10.1021/jf904542z

Cuco, R.P., Cardozo-Filho, L. and da Silva, C. (2019). Simultaneous extraction of seed oil and active compounds from peel of pumpkin (Cucurbita maxima) using pressurized carbon dioxide as solvent. The Journal of Supercritical Fluids, 143, 815. https://doi.org/10.1016/j.supflu.2018.08.002

Elfiky, S.A., Elelaimy, I.A., Hassan, A.M., Ibrahim, H.M. and Elsayad, R.I. (2012). Protective effect of pumpkin seed oil against genotoxicity induced by azathioprine. The Journal of Basic and Applied Zoology, 65(5), 289-298. http://doi.org/10.1016/ j.jobaz.2012.10.010

Fruhwirth, G.O., Wenzl, T., El-Toukhy, R., Wagner, F.S. and Hermetter, A. (2003). Fluorescence screening of antioxidant capacity in pumpkin seed oils and other natural oils. European Journal of Lipid Science and Technology, 105(6), 266-274. https:// doi.org/10.1002/ejlt.200390055.

Jiao, J., Li, Z-G., Gai, Q-Y., Li, X-J., Wei, F-Y., Fu, YJ., and Ma, W. (2014). Microwave-assisted aqueous enzymatic extraction of oil from pumpkin seeds and evaluation of its physicochemical properties, fatty acid compositions and antioxidant activities. Food Chemistry, 147, 17-24. http://doi.org/10.1016/ j.foodchem.2013.09.079.

Jimenez-Carvelo, A.M., Osorio, M.T., Koidis, A., Gonzalez-Casado, A. and Cuadros-Rodríguez, L. (2017). Chemometric classification and quantification of olive oil in blends with any edible vegetable oils using FTIR-ATR and Raman spectroscopy. LWT - Food Science and Technology, 86, 174-184. https://doi.org/10.1016/ j.1wt.2017.07.050

Lankmayr, E., Mocakb, J., Serdtc, K., Ballab, B., Wenzl, T., Bandoniene, D., Gfrerer, M. and Wagner, S. (2004). Chemometrical classification of pumpkin seed oils using UV-Vis, NIR and FTIR spectra. Journal of Biochemical and Biophysical Methods, 61 (1-2), $95-106 . \quad$ https://doi.org/10.1016/ j.jbbm.2004.04.007

Manaf, M.A., Man, Y.B.C., Hamid, N.S.A., Ismail, A. and Abidin, S.Z. (2007). Analysis of adulteration of virgin coconut oil by palm kernel olein using Fourier transform infrared spectroscopy. Journal of
Food Lipids, 14(2), 111-121. https:// doi.org/10.1111/j.1745-4522.2007.00066.x

Mandl, A., Reich, G. and Lindner, W. (1999). Detection of adulteration of pumpkin seed oil by analysis of content and composition of specific $\Delta 7$-phytosterols. European Food Research and Technology, 209(6), 400-406. https://doi.org/10.1007/s002170050516

Montesano, D., Blasi, F., Simonetti, M.S., Santini, A. and Cossignani, L. (2018). Chemical and Nutritional Characterization of Seed Oil from Cucurbita maxima L. (var. Berrettina) Pumpkin. Foods, 7(3), 30. https:// doi.org/10.3390/foods7030030

Naziri, E., Mitić, M.N. and Tsimidou, M.Z. (2016). Contribution of tocopherols and squalene to the oxidative stability of cold-pressed pumpkin seed oil. European Journal of Lipid Science and Technology, 118(6), 898-905. https://doi.org/10.1002/ ejlt.201500261

Nishimura, M., Ohkawara, T., Sato, H., Takeda, H. and Nishihira, J. (2014). Pumpkin Seed Oil Extracted from Cucurbita maxima Improves Urinary Disorder in Human Overactive Bladder. Journal of Traditional and Complementary Medicine, 4(1), 72-74. https://doi.org/10.4103/2225-4110.124355

Nurrulhidayah, A.F., Che Man, Y.B. and Rohman, A. (2014). FTIR Spectroscopy Combined with Chemometric for Analysis of Sesame Oil Adulterated with Corn Oil. International Journal of Food properties, 17(6), 1275-1282. https:// doi.org/10.1080/10942912.2012.689409

Ozulku, G., Yildirim, R.M., Toker, O.S., Karasu, S. and Zeki Durak, M. (2017). Rapid detection of adulteration of cold pressed sesame oil adultered with hazelnut, canola, and sunflower oils using ATR -FTIR spectroscopy combined with chemometric. Food Control, 82, 212-216. https://doi.org/10.1016/ j.foodcont.2017.06.034

Putri, A.R., Rohman, A. and Riyanto, S. (2019). Authentication of Patin (Pangasius micronemus) fish oil adulterated with palm oil using FTIR spectroscopy combined with chemometrics. International Journal of Applied Pharmaceutics, 11 (3), 195-199. https://doi.org/10.22159/ ijap.2019v11i3.30947

Rahayu, W.S., Rohman, A., Martono, S. and Sudjadi. (2018). Application of FTIR Spectroscopy and Chemometrics for Halal Authentication of Beef Meatball Adulterated with Dog Meat. Indonesian Journal of Chemistry, 18(2), 376-381.

Rezig, L., Chouaibi, M., Msaada, K. and Hamdi, S. (2012). Chemical composition and profile characterisation of pumpkin (Cucurbita maxima) 
seed oil. Industrial Crops and Products, 37(1), 8287. https://doi.org/10.1016/j.indcrop.2011.12.004

Rohman, A. and Che Man, Y.B. (2010). Fourier transform infrared (FTIR) spectroscopy for analysis of extra virgin olive oil adulterated with palm oil. Food Research International, 43(3), 886 - 892. https://doi.org/10.1016/j.foodres.2009.12.006

Rohman, A. and Che Man, Y.B. (2009). Monitoring of virgin coconut oil (VCO) adulteration with palm oil using Fourier transform infrared (FTIR) spectroscopy. Journal Food Lipids, 16(4), 618-628. https://doi.org/10.1111/j.1745-4522.2009.01170.x

Rohman, A., Che Man, Y.B. and Yusof, F.M. (2014). The use of FTIR spectroscopy and chemometrics for rapid authentication of extra virgin olive oil. Journal of the American Oil Chemists' Society, 91(2), 207213. https://doi.org/10.1007/s11746-013-2370-5

Spangenberg, E. (2001). Authentication of Vegetable Oils by Bulk and Molecular Carbon Isotope Analyses with Emphasis on Olive Oil and Pumpkin Seed Oil. Journal of Agricultural and Food Chemistry, 49(3), 1534-1540. https:// doi.org/10.1021/jf001291y

Zuhair, H.A., Abd El-Fattah, A.A. and El-Sayed, M.I. (2000). Pumpkin-seed oil modulates the effect of felodipine and captopril in spontaneously hypersensitive rats. Pharmacology Research, 41(5), 555-563. https://doi.org/10.1006/phrs.1999.0622 